\title{
Geografías de la otra orilla: \\ La uruguaya de Pedro Mairal y XXY de Lucía Puenzo
}

\author{
Geographies of the other shore: \\ Pedro Mairal's La uruguaya and Lucía Puenzo's XXY
}

\author{
MARÍA TERESA JOHANSSON M.
}

Universidad Alberto Hurtado, Chile.

mtjohans@uahurtado.cl

La geografía ficcional del Uruguay creada por la literatura y el cine argentinos expone un carácter utópico (Logie) inscrito en la representación de la ciudad de Montevideo, los balnearios y los paisajes agrestes, desde el prisma de una otredad idealizada (Chefjec). En este artículo se propone que el locus de la playa uruguaya opera como el paisaje primordial de este imaginario integrando rasgos de naturaleza y cultura. En ese marco, se analiza en las novelas La uruguaya de Pedro Mairal y la película $X X Y$ de Lucía Puenzo, la actualización de esa geografía ficcional y la configuración del locus de las playas, explorando el modo en que este paisaje (Andermann) despliega la potencia de corporalidades y formas de vida alternativas. En este sentido, se interpreta la configuración del Uruguay y sus playas como espacios de agencia afirmativa y crítica de normativas de género. Finalmente, se propone que estas producciones realizan un cuestionamiento crítico al imaginario tradicional del Uruguay asociado a la sociabilidad idealizadas para inscribirlo en una dinámica del tiempo presente.

Palabras claves: Pedro Mairal, Lucía Puenzo, Uruguay, espacios geográficos, playas.

The fictional geography of Uruguay created by Argentine literature and cinema exposes a utopian character (Logie) inscribed in the representation of the city of Montevideo, the beaches and the wild landscapes, usually observed from an idealized otherness (Chefjec). This article proposes that the Uruguayan beach locus serves as the primordial landscape of this imaginary including features from both nature and culture. In this context, the analysis of the novel La uruguaya by Pedro Mairal and the film $X X Y$ by Lucía Puenzo, together with the updating of that fictional geography and the configuration of the locus of the beaches, explore the way in which this landscape (Andermann) displays the power of both corporalities and alternative ways of life. Thus, the configuration of Uruguay and its beaches is interpreted as spaces of affirmative agency and critical of gender norms. Finally, the traditional imaginary of Uruguay associated with idealized sociability is critically questioned in order to inscribe it in a dynamics of the present.

Key words: Pedro Mairal, Lucía Puenzo, Uruguay, geographical spaces, beaches. 
La historia de la literatura argentina ha creado insistentemente diversas representaciones del Uruguay en páginas esenciales que han dado forma a una geografía imaginaria de la otra orilla del Río de la Plata ${ }^{1}$. Por tanto, la configuración imaginaria del país vecino posee una tradición literaria específica iniciada en los albores de la república, que fue profundizada a lo largo del siglo veinte mediante distintos géneros literarios. Los antecedentes más importantes de esta tradición, durante el siglo XIX, son La tierra purpúrea de William H. Hudson y, de manera más indirecta, Amalia de José Mármol, mientras que en el siglo XX se corresponden piezas emblemáticas como el famoso poema de Borges dedicado a la ciudad de Montevideo en su Luna de enfrente o el experimental L'Uruguayen de Copi (1972). A esa saga se sumaron las novelas contemporáneas Plata quemada de Ricardo Piglia (1997), Frivolidad de Juan Forn (1995), El aire de Sergio Chefjec (1992), El dock de Matilde Sánchez (1993), Los cautivos. El exilio de Echeverría de Martín Kohan (2000) y fragmentos de La vida descalzo de Alan Pauls (2011), por nombrar algunas que forman parte de la vasta lista en la que se inscribe la reciente novela La uruguaya de Pedro Mairal (2016).

Una investigación aledaña, intermedialidades mediante, permitiría anotar asimismo una tradición más reciente del cine argentino que ha tenido a Uruguay como locación y escenario de sus películas. En esta saga se inscribiría desde la temprana Piel de verano filmada en 1961 en Montevideo, Isla Gorriti y Punta del Este por Leopoldo Torres Nilssonhasta las más recientes $X X Y$ de Lucía Puenzo (2007), filmada cerca de Piriápolis, o La tercera orilla, dirigida por Celina Murga (2014). Las narrativas y películas mencionadas relatan viajes de argentinos, la mayoría provenientes de Buenos Aires en dirección a la República Oriental del Uruguay, un territorio alternativo que otorga refugios personales y políticos. Estas espacialidades de ciudades y balnearios, de ruralidades pueblerinas, o bien de paisajes indómitos y agrestes, se narran con tonos elegíacos, melancólicos, delirantes o realistas. Estos parajes albergan asimismo historias menores, relativas a un pasaje de veraneo por balnearios en cuyas playas es posible realizar estadías lejos de la urbe.

El breve ensayo "La parte por el todo. Alegato oriental", compilado en el libro El punto vacilante de Sergio Chefjec (2005), explicita esta tradición de la literatura argentina a la vez que profundiza en la potencia metafórica del Uruguay, para pensar una otredad constitutiva del imaginario nacional argentino: "Un fantasma acompaña al paisaje argentino, es la promesa de su reverso y la negación de su posibilidad" (Chefjec 2005: 35). Chefjec enfatiza que "su esencia se conjuga en subjuntivo" en el "como si fuera" y sostiene que los argentinos tienen una fascinación hacia Uruguay, "donde se mezcla el respeto hacia lo admirable y la debilidad ante la actualización de la nostalgia" (Chefjec 2005: 37). En su ficcionalización se proyectan representaciones que funden las nociones de territorio (la otra orilla), de la nación (la banda oriental) y del paisaje (azul y verdor). Finalmente, sentencia:

\footnotetext{
${ }^{1}$ Si bien buena parte de esta lista de autores y obras ha sido enumerada por distintos escritores y críticos literarios, entre los que se encuentran Sergio Chefjec, Ilse Logie, Martín Kohan, Marta Walderagaray en distintos ensayos y notas periodísticas, hemos agregado aquí nuevos títulos.
} 
"el Uruguay es una arcadia en clave rioplatense" (Chefjec 2005: 37). En el pensamiento de la arquitecta Graciela Silvestri (2004), para los argentinos el imaginario del Uruguay se verifica como "una arcadia política que (...) se condensa en una figura paisajística, la costa urbanizada del Río de la Plata -que en la orilla uruguaya llaman mar-" (Silvestri 2004: s/p).

Por otra parte, Ilse Logie (2013) acuña el término de geografía ficcional para referirse a la imaginación literaria de los países vecinos. En su artículo "Geografías ficcionales: el Uruguay de Copi" sostiene que en la poética de Copi "el Uruguay se presenta como exageración grotesca y burla del tradicional imaginario argentino acerca del país vecino, de índole utópica" (Logie 2013: 15)². Destaca la autora a ese respecto un "fuerte potencial alegórico" que extremaría, entonces, esta condición metafórica ${ }^{3}$. Tal como es propuesto por varios críticos literarios, las experiencias de cruce del Río de la Plata, el emplazamiento en el territorio vecino, la descripción de una ciudad idealizada y la descripción de un paisaje alternativo a la pampa argentina, han conformado al interior de la literatura argentina una espacialidad ficcional del Uruguay, con un marcado impulso utópico en el cual pueden distinguirse -a grandes rasgos- dos tendencias gravitantes: una de carácter más urbano y otra asociada al paisaje de naturaleza. Ambas tendencias exponen una interdependencia entre imaginación del espacio y utopía, actualizando una vasta orientación de la literatura latinoamericana ${ }^{4}$.

A partir de lo anterior, los autores y críticos coinciden al identificar tanto en la dimensión metafórica como en la deriva alegórica del Uruguay, un rasgo constitutivo de la literatura argentina, asociada a su vez a un espacio político de sociabilidad que cumple las promesas de ciudadanía moderna y a una naturaleza idealizada ${ }^{5}$. En el primer sentido, estos imaginarios espaciales configuran la representación del territorio oriental en el sentido de una oposición entre Buenos Aires y Montevideo, puesto que distintos textos ficcionalizan recorridos pausados y nostálgicos por esta ciudad en los que se reconoce una temporalidad

\footnotetext{
${ }^{2}$ Tal como lo plantea Logie (2013), para el caso de la Argentina el 'otro' más cercano es, desde luego, la República del Uruguay, y el texto que plasmó la supuesta 'identidad' uruguaya del modo menos convencional y más rupturista es, sin lugar a dudas, la novela breve L'Uruguayen (1972), de Copi. En este texto, "el Uruguay se construye como un artefacto, un objeto artístico que ha roto sus amarras con el referente extratextual y que al lector le parece absurdo" (Logie 2013: 3).

${ }^{3}$ Asimismo, Logie recoge las palabras de César Aira, quien en su análisis de L’Uruguayen sostiene que: "El Uruguay es una Argentina miniaturizada, es decir, objeto artístico a priori”; en este sentido, concluye que el Uruguay resulta "el paisaje obligado del escritor argentino", "lo inverificable, la ficción" (Logie 1991: 20).

${ }^{4}$ Tradicionalmente, las categorías de espacio y utopía han sostenido una implicancia mutua devenida de la etimología del término utópico como no-lugar.

${ }^{5}$ Marta Waldegaray lo plantea en los siguientes términos: "Todo lo expuesto parece configurar el lado oriental del Plata como un espacio transitivo, un imaginario declinado según las experiencias del exilio, la libertad, la fuga, el escape, la recomposición personal, la proyección política, el refugio, el placer de la pereza. Lo oriental rioplatense es espacio intermedio, estado de suspensión temporal, tiempo estancado, respiro, aire" (Waldegaray 2013: 11).
} 
y una forma de sociabilidad perdidas ${ }^{6}$. Esta tendencia de orientación urbana convive con un segundo impulso, en el que la imaginación geográfica deja la ciudad para adentrarse en grandes extensiones de campos ondulantes o para situarse en las amplias geografías de borde costero, donde aparece un locus particular: la playa uruguaya. La imaginación ficcional del Uruguay, es entonces dependiente de su nexo con la configuración de la ciudad balnearia y del espacio natural de las playas, dada la extensión de su borde costero. Por su parte, el imaginario de Montevideo también ha integrado, a la playa extensa que bordea la ciudad, pues mientras Buenos Aires se emplaza de espaldas a la ribera del Río de la Plata, Montevideo se proyecta desde una rambla abierta al litoral. Por tanto, la playa uruguaya se representa en la literatura argentina como un paisaje cultural específico constituido mediante dispositivos de valoración, idealización y apropiación, en el que se despliega una potencia particular?. Tal como lo señala Andermann: "El paisaje, lejos de ser apenas el medio de contención del dinamismo movilizador del espacio, debería entonces pensarse también como expresión de la potencialidad latente del lugar, potencialidad que remitiría precisamente a un orden espacial alternativo" (Andermann 2008: 14).

Las geografías ficcionales del Uruguay elaboradas en la novela La uruguaya de Pedro Mairal y la película $X X Y$ de Lucía Puenzo manifiestan la potencialidad latente de un orden espacial alternativo. Ambas producciones elaboran una mirada preferente al locus de la playa uruguaya, constituido como un entorno, una imagen y una materialidad sobre los que operan distintos sentidos culturales. En estos imaginarios del territorio uruguayo se reinscribe críticamente una condición de espacio de refugio, o bien, de escenario utópico, donde se reconfiguran las identidades de género y la figura de sujeto nacional. Lo anterior hace posible considerar que en estas producciones se elabora una nueva expresión del carácter de frontera y de duplicación que tiene Uruguay con respecto a los discursos nacionales argentinos, mediante un espacio que tensiona las relaciones entre identidad y otredad, entre lo mismo y lo propio, y aquello que es extraño y ajeno.

En la novela de Pedro Mairal, estas cuestiones se vinculan también con las representaciones de la figura de un autor dependiente o tributario de un espacio para la circulación libidinal de la economía capitalista. En el film de Lucía Puenzo, por su parte, los regímenes de género se construyen a través de la inscripción material del cuerpo en el

\footnotetext{
${ }^{6}$ En el libro Utopias urbanas: geopoliticas del deseo en América Latina, Gisela Heffes (2013) especifica esta relación entre deseo utópico y ciudades como una tendencia más amplia de la literatura latinoamericana; ella lo expone en los siguientes términos: "Es, más aún, el territorio urbano el que condensa un imaginario cultural significativo, uno que, en sus múltiples formas, procura materializar las proyecciones provocadas por los deseos e imaginaciones de una sociabilidad diferente a la real y que, por lo tanto, conforma propuestas espaciales alternativas" (Heffes 2013: 20).

${ }^{7}$ Jens Andermann (2000) en el libro Mapas de poder realiza una arqueología literaria del espacio argentino. Siguiendo esta orientación, una investigación de carácter genealógico debiera atender el modo en que la representación de los espacios correspondientes al territorio geográfico uruguayo, interactuó con el discurso territorial sobre la nación argentina, que, tal como lo postula Andermann, presenta en los inicios de la república tres dispositivos consecutivos: la apercepción, la apreciación y la apropiación (Andermann 2000: 18-20).
} 
paisaje del borde costero. En ambas obras se presenta inicialmente un locus amoenus de la playa uruguaya, una locación de la otredad en estado natural, "paradisíaca" o liberadora, que permite formas de vida eximidas de las convenciones sociales impuestas por las dinámicas nacionales de la vida citadina de Argentina, pero que progresivamente pierde su carácter utópico. Por tanto, estas playas conforman un paisaje -en el sentido propuesto por Andermann $(2008,2013)-$, de una imagen cultural de la naturaleza que tensiona la relación entre espacio y lugar y que define los "diferentes modos de articulación entre, por una parte, un cuerpo y su aparato sensorial y, por otra, la extensión hacia donde avanza este cuerpo en busca de aperturas y de asentamiento" (Andermann 2013: 34). Se trata de un paisaje que participa del "propio proceso de poner en relación, de forjar agenciamientos, entre cuerpo y entorno" (Andermann 2013: 35).

\section{La uruguaya de Pedro Mairal}

El Uruguay imaginado en la novela de Pedro Mairal es tanto una geografía ficcional que integra la ciudad de Montevideo a los distintos paisajes de playas como un espacio de circulación y liberación en el cual se intenta restituir una figura de autor. En La uruguaya, el devenir del protagonista intenta una restauración de una figura de la masculinidad típicamente hegemónica que, si bien será tempranamente frustrada, se proyectará mediante el deseo erótico que funciona como una maquinaria narrativa pulsional; la circulación libidinal del flujo de capital y la reposición de una identidad de escritor que se sostiene en la posibilidad de escritura como un horizonte vital.

La novela narra el viaje durante un día a Montevideo de un escritor, padre de un hijo pequeńo, afectado por una crisis matrimonial severa. Se trata de una crisis provocada, entre otras causas, por una situación de cesantía y endeudamiento. Lucas, el escritor que comparte algunos rasgos de carácter autoficcional con el autor ${ }^{8}$, lleva varios años sin escribir ni ejercer una actividad productiva. Amenazado, abandonado y rechazado por su mujer, el narrador atraviesa un trance amoroso, sexual y económico, en el que tanto la figura de masculinidad tradicional como la figura del escritor son desestabilizadas. "Mastiqué mis dudas, mis inseguridades. Era mi actitud de desempleado, de tipo que no provee, mi impotencia de macho cazador, pidiéndote si podías hacerme una transferencia" (Mairal 2016:18).

\footnotetext{
8 "Hubo un viaje a Valizas, fuimos invitados con Cucurto, y después algún viaje a Montevideo, ahí empezó una idea. Me interesaba mostrar ese parecido con la Argentina, un sí pero no. Tiene algo del otro lado del espejo: Montevideo me produce, todo el tiempo, un extrañamiento. La sensación de que es familiar pero no; como en los sueños, donde la gente es pero no es quien es. Estás caminando y parece una parte de Buenos Aires pero, a la vez, las marcas son otras o, de golpe, de fondo en la calle se ve el agua. Ese tipo de cosas me fascinan" (Tentoni 2016).
} 
Los antecedentes que condicionan el cruce por el Río de la Plata y la estadía de un día en Montevideo, inscriben de manera explícita un contexto político-económico nacional que se expone bajo los términos de la imposibilidad, la contracción, el sometimiento y su contracara privada e íntima, expresada en términos de abstinencia, rechazo sexual y desamor. Argentina es la nación de la crisis, la desestabilización de la moneda, las restricciones económicas, en donde impera la falta y la deuda. En ese contexto, es imposible ejercer una condición laboral ligada a la escritura literaria ni ostentar el tradicional rol del escritor argentino. Bajo esas condiciones, Lucas recibirá el pago anticipado de derechos de autor desde España y Colombia, y decidirá, por una razón de conveniencia en el cambio monetario, viajar a buscar dicho pago a Uruguay. Esto le dará la chance para reencontrarse con la joven a quien había conocido el verano anterior durante una reunión de escritores que había tenido lugar, justamente, en las playas rochenses.

La posición de endeudamiento en la que se encuentra el protagonista es generadora de una retórica del ridículo risible que articula en la novela una secuencia discursiva con una contexto social. Por tanto, es posible interpretar que "el capitalismo global lleva la relación deudor-acreedor a su extremo y al mismo tiempo la socava: la deuda se convierte en un exceso abiertamente ridículo" (Zizek 2016: 59). La retórica del ridículo se formula en la novela con un tono humorístico, tributario de un estilo de cercanía en torno a experiencias corrientes, domésticas y mundanas. La vivencia vertiginosa y fracasada de la fantasía restaurativa de la figura de autor es narrada irrisoriamente como una deriva condenada al fracaso, guiada por la pulsión erótica y el flujo de mercado. Así, la novela conjuga en la geografía ficcional del Uruguay las pulsiones del deseo sexual con los flujos libidinales del dinero en una operación que actualiza lo que puede denominarse como una retórica de la seducción ridiculizada, pues, tal como sostiene Chefjec, "es consabida también la seducción que ha ejercido la Banda Oriental en amplios sectores medios y altos: un cambio de registro para la placidez veraniega, el refugio bancario y el juego de fin de semana" (Chefjec 2005: 37).

Por otra parte, en el imaginario narrativo, y como contracara de Argentina, el territorio del Uruguay, no solo será el paraíso fiscal donde se puede recibir dinero desde el extranjero, sino el espacio donde Lucas afirma un reconocimiento, considerablemente precario, de su condición de escritor, narrado humorísticamente en el episodio del encuentro de escritores latinoamericanos de la playa rochense de Valizas. El paisaje de la playa rochense en el que tuvo lugar el encuentro de escritores expresa todos los atributos asociados a un imaginario idealizado: "arena blanda por todos lados, calor, puro hedonismo playero" (Mairal 2016: 25). En ese espacio ficcional de uruguayismo costero, se inscribe una representación burlesca del campo literario que alberga a "los intelectuales latinoamericanos armando nuestro número, hablando para nosotros mismos en un balneario" (Mairal 2016: 26). Este lugar utópico es el escenario para la regresión juvenil sufrida por el narrador en su encuentro con la joven uruguaya Guerra con quien realiza un recorrido hacia Cabo Polonio al día siguiente. El tono de comedia que narra la aventura erótica no se hace esperar en el recuerdo del paseo hacia Cabo Polonio, un pasaje en el que el cuerpo y el entorno entran en una relación compenetrada: "Subimos un médano, el primero de muchos y lo bajamos 
enterrando los pies en la arena hasta la pantorilla" (Mairal 2016: 38). En un lenguaje que construye una suerte de utopía satírica, las dunas descritas con rasgos hiperbólicos ostentan un carácter de naturaleza romántica intervenido por la imagen de un espectáculo tecnológico: "Otro médano más y ahí en la cumbre miramos el estallido del mar, un brillo de explosión atómica" (Mairal 2016: 38).

En lo que sigue, el locus específico de la playa uruguaya se elabora a partir de un contrapunto narrativo entre dos paisajes, el de la playa edénica y la playa citadina devastada. Para conformar esta oposición, la novela actualiza por una parte, el recuerdo de Valizas con sus dunas orientadas hacia Cabo Polonio y, por otra, la visita en el presente a la playa popular montevideana cercana al Parque Rodó. En el presente narrativo, el personaje se proyecta en la playa de Montevideo con la joven uruguaya: "Quedamos tirados de costado en la arena. Me vas a matar, Guerrita. Siempre en la arena nosotros" (Mairal 2016: 126). En ambos escenarios playeros, la materialidad de la arena se vuelve protagónica; el solo hecho de pisarla concretiza una forma especial de estar en el mundo, sobre un terreno que afecta la corporalidad erguida. La particularidad del movimiento y de la disposición del cuerpo en la arena da pie para el despliegue de una expectativa erótica narrada con destreza y comicidad pero frustrada en ambas oportunidades debido a la irrupción de un tercero que obstaculiza el encuentro. En la playa edénica de Valizas, este personaje toma la figura del turista, mientras que en la playa citadina irrumpe el ladrón que roba los dólares, acabando con la máquina pulsional que impulsaba al sujeto deseante: "Yo estaba de espaldas al mar y de ese lado vinieron los dos tipos" (Mairal 2016: 129).

Esta escena expone que la playa ya no es un lugar a salvo; por el contrario, el estar en la arena acrecienta la vulneración ante el despojo involuntario y violento. La calidad de espacio utópico de la playa uruguaya es arruinada por la violencia de una banda delincuencial de la cual la joven pudo ser parte: "¿era una cheta medio rea o era medio lumpen?” (Mairal 2016: 36), se pregunta el narrador en el recorrido desde Valizas hacia Cabo Polonio, haciendo énfasis en la incapacidad de distinguir clases sociales producto de su extranjería. El fin de la fantasía impulsada por la fuerza libidinal originada en el pago de los derechos de autor hará explotar el locus de la playa uruguaya mediante una acción violenta de despojamiento. Así, la novela vuelve cierta la imposibilidad de proyectar un afuera respecto del espacio totalitario del mercado. Este episodio reafirmaría la idea propuesta por Marta Walderagaray respecto de la representación simbólica del Uruguay, en el sentido de una prolongación del contexto argentino: "El otro lado del río, comporta una distancia vital pero no una lejanía vital. La Banda Oriental está contaminada del sentido político del otro lado" (Waldegaray 2006: 108).

Por otra parte, la representación de la ciudad de Montevideo también es afectada por la imposibilidad resguardar un territorio a salvo o "una arcadia política", y aparecerá con un carácter ambivalente. En un inicio, en el recorrido que realiza el protagonista, se reconoce la conservación de rasgos propios de una economía y modos de vida del pasado, lo que genera la consabida nostalgia por una forma de vida social y cívica idealizada en el imaginario argentino: "En este primer tramo todo estaba en un tono menor, como si no hubiera habido 
neoliberalismo, sin glamour capitalista" (Mairal 2016: 49) pero, progresivamente, en las calles montevideanas el narrador experimentará la aceleración y el vértigo asociados a la activación del ritmo del capital mediante el gasto monetario desmedido.

A lo largo de la novela, el recorrido por Montevideo es descrito como una pasaje de idea y vuelta por avenida 18 de julio. Parafraseando la lectura de Jens Andermann (2000) en Mapas de poder, donde analiza los dispositivos de miradas y actitudes en las primeras configuraciones escriturales del espacio argentino (Andermann 2000: 20), es posible sostener que el narrador de La uruguaya ejercita, junto a la mirada, los dispositivos del recuerdo, la audición, el intertexto y la intermedialidad como mecanismos sobre los cuales operan la cita y la reescritura en torno un país y una ciudad ya inventada literariamente en una amplia producción de literatura rioplantense. Al respecto, es interesante destacar la intertextualidad con el poema de Borges tanto como la referencia a la escena de El pozo (1939) de Onetti y la amplia inclusión de letras de canciones de música popular que la novela actualiza.

Como hemos señalado, el viaje a Montevideo, guiado por la actualización de un dispositivo de reconocimiento y por la fantasía de la circulación del capital ligado al encuentro erótico, culmina en un escenario de la playa urbana degradada que condensa un territorio fronterizo donde la naturaleza limita con la fuerza productiva del paisaje urbano. En ese locus se clausura el imaginario del Uruguay con carácter utópico. Esto lo constatan las palabras del personaje Enzo, una figura deformada de crítico y autor uruguayo. "Acá hay como un triángulo de las Bermudas. El lado B del Río de la Plata, ese otro lado, eso te come, te liquida. (...) Hay que tener cuidado con Uruguay, sobre todo si venís pensando que es como una provincia argentina pero buena" (Mairal 2016: 143). En este sentido, los tradicionales dispositivos idealización, valoración y apropiación del territorio uruguayo serán impactados por el despojamiento. Cabe señalar que en este gesto de desmitificación que propone la novela, se rearticulan los términos de la relación entre Argentina y Uruguay, signada en el orden socioeconómico por una apropiación vacacional e inmobiliaria de argentinos sobre el territorio oriental y por el imaginario de la provincia. ${ }^{9}$ Así, en la geografía ficcional del Uruguay aparece reelaborada al integrar nuevos flujos del capital transnacional y ordenes de mercado donde se despliega una desmitificación del paisaje de la playa y la abolición de los elementos identitarios hegemónicos.

Por otra parte, la novela también anula la tradicional figura del escritor bonaerense al degradarlo en su condición masculina a través de una caída esperpéntica. Se constata entones que esa posición de género no tiene lugar en el tiempo contemporáneo, cuestión que es subrayada en la escena del retorno a Buenos Aires. De esta manera, Mairal subvierte simultáneamente varios imaginarios nacionales argentinos hegemónicos. Al despojar a la playa uruguaya de su condición utópica de naturaleza idealizada para situarla en un borde del espacio geopolítico citadino, violento y bárbaro horada de paso, la idea de la virtuosa sociabilidad uruguaya, mediante una operación crítica y desmitificadora que revierte el sentido tradicional.

${ }^{9}$ El flujo del turismo de argentinos hacia las playas del Uruguay y la compra de terrenos en la costa por parte de estos registran un crecimiento sostenido. 


\section{$X X Y$ De LuCía Puenzo}

El film $X X Y$ de Lucía Puenzo ha concitado un amplio interés por parte de la crítica en torno a la problemática de género. Para Nuria Calafell (2014), la figura intersexual de la protagonista de nombre Álex, pone en escena un cuerpo en conflicto que debe realizar una elección y que en su condición de abyecto ejerce una crítica hacia las construcciones normalizadoras del deseo y la sexualidad ${ }^{10}$. En general, la crítica se ha centrado sobre esos aspectos sin necesariamente integrar en esa problemática la pregunta por las dimensiones espaciales. Como es sabido, la película $X X Y$ fue filmada en los alrededores de Piriápolis, Uruguay, por lo que pone en escena una locación situada en la otra orilla del Río de la Plata y actualiza, asimismo, elementos relativos al imaginario argentino del país vecino. En este sentido, es posible leer algunos de los tópicos sobre el territorio oriental, especialmente relativos al locus de la playa uruguaya, ensamblados con la problemática de identidades de género y dirimidos en el cuerpo de la protagonista.

No se trata de una película que elabore la conciencia del personaje, sino de una exterioridad que deja entrever una subjetividad errática, cerrada y vuelta sobre sí. La mirada de la cámara sobre la joven no pretende interiorizar sino seguir una forma, la de un cuerpo en devenir que se expone como imagen de un trayecto desde el interior de la casa hacia el exterior del borde costero: mar, arena, bosques de playa delinean un entorno natural solidario con la imagen del cuerpo de la protagonista. El paisaje de la playa se configura entonces como una superficie material en la cual se inscribe el cuerpo de Álex, una potente imagen liminal detenida en el tiempo de la decisión sobre su género. Así, a lo largo del filme, el paisaje de la playa se carga de significados culturales y políticos, anclándose en un sentido de experiencia material que opera en conjunto con una imagen de naturaleza. Moira Fradinger (2016) en su interpretación de $X X Y$ propone la denominación de cuerpos anfibios al asociar el cuerpo intersexual con la presencia de otros seres vivientes que se encuentran en el ambiente costero, entre estos, los anfibios, reptiles y en especial las tortugas marinas en peligro de extinción ${ }^{11}$.

\footnotetext{
${ }^{10}$ Tal como lo expresa Javier Guerrero, en términos generales y teóricos: "este discurso de lo abyecto implica ambigüedad en torno al cuerpo, se refiere a lo informe, deviene precisamente en la reducción necesaria que fortalece la oposición sexual normativa tras citar una escena de exclusión. Al no gozar de subjetividad, los seres abyectos carecen de género, cuestionando en sí mismos la humanidad a partir de semblanzas amenazantes, perturbadoras y monstruosas" (Guerrero 2014: 23).

${ }^{11}$ Sostiene Moira Fradinger: "Si el peligro de visibilidad es un tropo clásico en narrativas trans e intersex, el 'escondite' que protege de dicho peligro es lo que la crítica ha entendido del bosque donde vive la familia. Sin embargo, dicho escondite es en realidad función de otra visualización: de aquello que la ciudad esconde. El entorno geográfico costero muestra sus íntimas convivencias de arena, mar y árboles, sin la intrusión gris de edificios, barroca de catedrales, suntuosa de palacios o sangrienta de hospitales. Esa intimidad nos orienta en el tiempo no lineal de los ciclos del agua; sus anfibios y cangrejos nos ofrecen figuras tentaculares con que imaginar las microrrelaciones entre todo lo viviente" (Fradinger 2016: 380).
} 


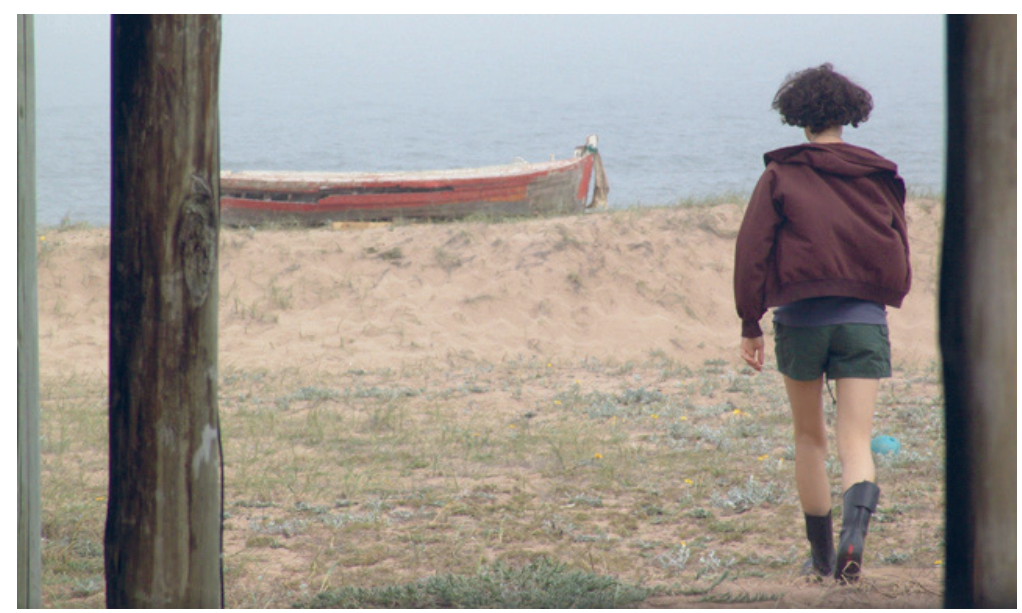

La película $X X Y$ visibiliza, a partir del paisaje, el entorno y la locación geográfica, varias líneas interpretativas que han sido referidas en los apartados anteriores, actualizando dimensiones imaginarias y materiales para el espacio de la otra orilla. En primer lugar, Uruguay se confirma una vez más como el espacio del refugio y del asilo ante situaciones de persecución y de agresión. Pero, obviamente, no ha sido este el primer viaje de los padres de Álex al Uruguay; por el contrario, la misma playa uruguaya configura el pasado originario de la trama familiar que en el presente alberga un carácter enrevesado y, en parte, siniestro, ya que la playa fue el lugar idílico del encuentro amoroso entre los padres. Tal como lo relata la madre con un gesto indicial en una posición de testigo que refiere un aquí original, la concepción de Álex tuvo lugar entre el roquerío. El paisaje de la playa rocosa materializa un carácter sólido, oscuro, pedregoso, que alegoriza la historia familiar. La playa uruguaya se despliega entonces con mayor complejidad y funde imágenes heterogéneas, haciendo coexistir la playa de arena, la playa rocosa y la playa boscosa donde ocurren los movimientos de fuga, libertad, pero también de dureza e inclemencia. En este espacio natural es posible generar relaciones de afectividad, a pesar de la permanente atmósfera de enrarecimiento que pervive en todas las escenas.

La familia de Álex ha decidido trasladarse al país vecino para huir del rechazo y la mirada ofensiva de la sociedad argentina y para que él pueda crecer libremente. Ante la violencia amenazante de Buenos Aires, se aspira a encontrar en esa otra orilla del Río de la Plata un asilo. En cierta medida, se reitera la dicotomía metrópoli/ruralidad regional que sostiene la relación entre Buenos Aires y la provincia, pero trasladándola a la dicotomía Buenos Aires/borde costero uruguayo. En esta representación se ejercita un dispositivo de apropiación del territorio, unido a una superioridad cultural de corte nacionalista que se manifiesta en la generación de los padres de manera algo extemporánea, pero que es desarmada en la generación de los hijos por nuevas relaciones afectivas de integración. 
La imagen pueblerina del Uruguay se cifra en los personajes uruguayos configurados como los pescadores nativos de la zona: sujetos populares instalados en una dimensión histórica cuasi premoderna, fuera de la racionalidad científica, del mercado y de la industria. Sin embargo, la imagen natural de la playa también acaba intervenida por la violencia, primero por los golpes que propina el padre al hijo del pescador a causa de su traición a un pacto de silencio, y luego por la agresiva persecución que sufre Álex en la playa por parte de muchachos lugareños, impedida por la aparición del amigo uruguayo de Álex, hijo del pescador agredido. Al igual que en la novela de Mairal, la violencia sobre el cuerpo irrumpe en el imaginario de la playa uruguaya y desmitifica su condición de pureza.

Por otra parte, la película actualiza también el motivo del cruce del Río de la Plata que, al igual como sucede en la novela La uruguaya, estructura la narrativa al marcar el inicio y el cierre del relato. El guión se articula en torno al viaje de una familia porteńa que acude a pasar unos días en la casa familiar de Álex para evaluar un futuro tratamiento. En lo que dura esta estadía, la figura del médico cirujano bonaerense, exponente de la masculinidad hegemónica anclada en los discursos científicos y en la ambición capitalista, es expuesta y sometida a una crisis por la acción de su propio hijo. La solidez y la herencia del patriarcado son quebradas por la aparición del hijo joven, un adolescente cuya ambigüedad sexual e indeterminación viene a manifestarse en Uruguay y a fisurar el orden patriarcal. La concreción del gesto rebelde condensado en el encuentro con Álex se produce justamente en "la otra orilla", donde se vuelve posible pensar en otra configuración de las relaciones entre identidad y otredad, y donde es posible liberar estereotipos y formas hegemónicas.

Para los padres de Álex -es decir, para una generación anterior-, el emplazamiento en el Uruguay contiene un potencial metafórico de una nueva comunidad política: funciona como un espacio de refugio al que es necesario recurrir para aliviarse de la violencia de los estereotipos sociales urbanos. No obstante, para los adolescentes, el paisaje de la playa uruguaya ya no cumple una función metafórica, sino que expresa una inmanencia de la desterritorialización. El nuevo trío de jóvenes en el que participa activamente el joven uruguayo, conforma una comunidad de cuerpos que se adosan en su extrańamiento, que se protegen en una nueva fórmula de alianza política venidera.

En la película $X X Y$, el paisaje de la playa uruguaya, que al mismo tiempo es entorno e imagen ${ }^{12}$, se expone como un locus privilegiado para distintas operaciones, pues no está agotado ni inmovilizado, sino que despliega activamente una potencia de vida y naturaleza, más allá de toda convención y de toda ideología basada en dicotomías preestablecidas. La ambigüedad y las formas liminales del propio territorio le son inherentes. En este se expresa

\footnotetext{
${ }^{12}$ Es posible pensar que la película recupera un sentido de paisaje que justamente se sitúa en el límite entre imagen y entorno: "lo que habría que recuperar es una noción del paisaje que supiera dar cuenta de su posición intersticial y oscilante entre imagen y entorno, como aquello que ensambla la construcción perceptiva con los efectos que ésta produce en la materialidad de lo que abarca, siendo ella misma efecto de la luminiscencia móvil del mundo material. Paisaje-ensamble, o imagen-movimiento: es hacia esa cinemática natural pos-kantiana, creo, que habría que avanzar a fin de construir la historicidad del paisaje y, así, dotarlo nuevamente de futuridad" (Andermann 2008: 6).
} 
la indistinción entre identidad y otredad y, por lo tanto, el cese de las dicotomías argentino/ uruguayo, masculino/femenino, hombre/mujer, burgués/proletario, artista/oficio. Así, la escena de la ronda de jóvenes alrededor del fuego constituye la imagen de una nueva alianza política, sostenida materialmente en la corporalidad que expresa la obsolescencia de la identidad fija de género. En el paisaje de la playa uruguaya ha sido posible, entonces, la emergencia del encuentro alternativo, configurando una experiencia que no solo expresa la crisis del aparato ideológico de la modernidad y sus categorías dicotómicas, sino que también da espacio a la emergencia de una nueva forma de vida en plural y en estado de vitalidad natural. Es esta forma vital la que se materializa en el cuerpo de Álex. Su cuerpo demarca un lugar de pasaje y un borde, un encuentro entre dos formas genéricas que establece una continuidad material con el paisaje de la playa, justamente en esa condición de "textura neutra" y en su carácter liminal.

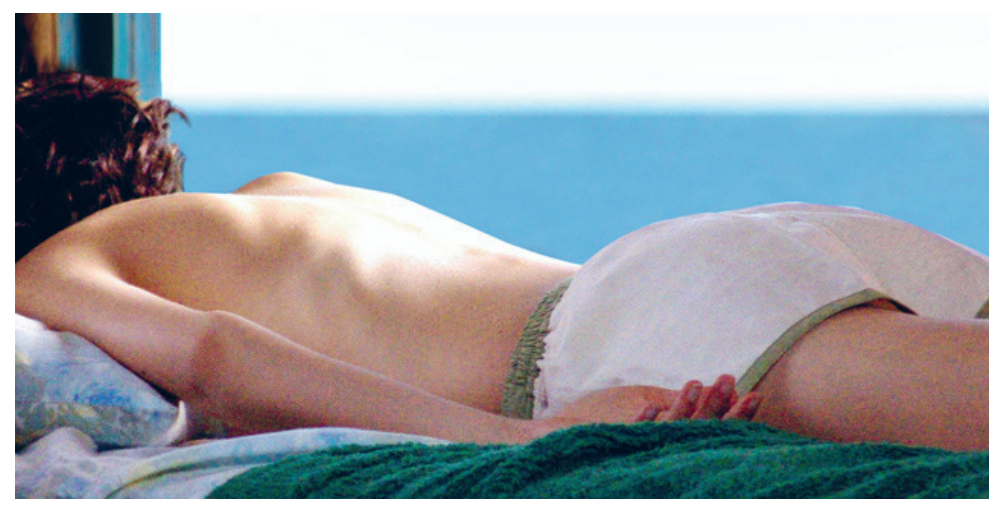

Desde una perspectiva comparativa, las siguientes notas de Alan Pauls (2006) sobre los sueños en la playa, escritas en Cabo Polonio, introducen un modo de concebir la geografía ficcional de $X X Y$ de Lucía Puenzo:

si se sueña mucho es porque la playa es un territorio libre de imágenes (...) La arena y el mar toleran mal la actualidad de las imágenes, no su potencia. (...). Porque los paisajes de la playa tienen una textura homogénea, neutra como de soportes o superficies (Pauls 2006: 12).

La imagen de la playa uruguaya aparece como continuidad exterior del cuerpo de Álex, pues la cámara se detiene de manera dilatada y reiterativa en la progresión territorial entre cuerpo, arena y mar, la que funda una relación metonímica entre los bordes del género, el encuentro erótico y el espacio liminal de la playa. El emplazamiento para esa transformación de los regímenes discursivos y materiales sobre el género es el paisaje utópico de la playa uruguaya, donde se actualiza su nuevo estatuto performativo e inestable. 


\section{NOTAS DE CIERRE}

En el citado ensayo de Sergio Chefjec (2005), el escritor argentino anota que el imaginario geográfico del Uruguay en la literatura argentina hace confluir los sentidos de una localización ideológica política, de una operación geográfica imaginaria y de un topos representacional. Se podría sostener que estas tres dimensiones oscilan entre la imaginación de paisaje de naturaleza y de ciudad; mientras la primera combina los campos ondulados con un amplio litoral de sus extensas playas de borde, la segunda otorga una atención cartográfica y afectiva a la ciudad de Montevideo. De esta manera, las imágenes desplegadas de Montevideo y del territorio natural de Uruguay concilian los sentidos de nación y de paisaje en una geografía ficcional que no expresaría lo otro en términos de diferencia radical, sino que en términos de duplicación y disimilitud. A partir del ensamble entre los atributos de espejo borroso y frontera porosa, se genera un espacio en el que aparece una relación de convivencia entre la identidad y la otredad, una experiencia de lo mismo, pero trastocado por diferencias sutiles que combinan dimensiones presentes e imaginarios utópicos. Justamente, la representación del Uruguay como espacio de la otredad territorializada, de la ficcionalización de lo distinto, no establece del todo contrapuntos nacionalistas ni fronteras demarcadas, sino una operación de sincronías, duplicaciones, coexistencias que se basan en un mapa cognitivo de superposición, de capas geográficas y culturales que se articulan de manera diversa. Estos elementos configuran una trama que puede leerse en la que se dirimen las dimensiones de una identidad nacional, pero también otras identidades, tales como las de género o las artísticas. En este sentido, ambas producciones podrían leerse como "contranarrativas" de la nación argentina, que, según Bhabha, serían las que "evocan y borran sus fronteras totalizantes, tanto fácticas como conceptuales, alteran esas maniobras ideológicas a través de las cuales 'las comunidades imaginadas' reciben identidades esencialistas" (Bhabha 2002: 185). En la novela de Mairal, la geografía ficcional del Uruguay aparece revisitada e integrada a ciertas economías libidinales, a nuevos flujos del capital y retóricas eróticas que se ensamblan subvirtiendo categorías fijas de género en un espacio alternativo: el Uruguay imaginado, donde el sujeto tiende a la desrealización de los supuestos identitarios hegemónicos y de las figuras de autor tradicionalmente legitimadas. Por su parte, $X X Y$ elabora una geografía ficcional del Uruguay como refugio para la posibilidad de sostener una indeterminación de género, libre de agresiones, al tiempo que articula el motivo del cruce del Río de la Plata como un viaje de ruptura con los modelos hegemónicos nacionales argentinos. Paralelamente, los dispositivos de refugio personal, político, económico y social, operan en ambas producciones, pero son puestos en crisis por la condición de indeterminación del paisaje de la playa. De esta manera se produce un ensamble entre el imaginario argentino de los espacios geográficos de la costa uruguaya y los desplazamientos físicos e ideológicos. ${ }^{13}$ En el paisaje de la playa, la aparición de la

\footnotetext{
${ }^{13}$ Un sentido convergente con el postulado anterior se encuentra en el estudio de Javier Guerrero (2014) sobre artistas latinoamericanos: "Asimismo, estos autores y la lectura que propongo sobre ellos complican la noción de
} 
pulsión erótica despliega su potencia crítica, al tiempo que las distinciones de género logran entrar en un proceso de suspensión de los órdenes impuestos. Pero, si bien la construcción de este paisaje con rasgos de uruguayismo resguarda un lugar para el surgimiento de un principio de vitalidad, para la expresión de la otredad y para la interrogación crítica de la nacionalidad, no es posible restarlo de la amenaza de agresión y violencia. Así, estas ficciones e imágenes cifran un particular fracaso del imaginario de arcadia natural y política ante la imposibilidad contemporánea de imaginar la playa uruguaya como un locus o una superficie de borde y otredad idealizados. En la imagen del Uruguay y de sus playas que estas obras proponen, se puede reconocer entonces, tanto los elementos virtuosos del encuentro, la libertad y la afirmación, como los rasgos de la desmesura y el exceso, la acción violenta. En estos sentidos, el paisaje natural se desestabiliza junto a la noción de utopía al tiempo que la configuración imaginaria del país vecino es puesta en crisis. En ambas producciones, por tanto, la playa uruguaya se constituye en su condición histórica, es decir, como una imagen cultural traspasada por el devenir del tiempo presente.

\section{OBRAS CITADAS}

Andermann, Jens. 2014. "Exhausted Landscapes: Reframing the Rural in Recent Argentine and Brazilian Films". Cinema Journal, 53(2): 55-70.

. 2013. "Reverón: el paisaje evanescente". Tóp. Sem 29: 33-52. Disponible en: <http://www.scielo.org.mx/scielo.php?script=sci_arttext\&pid=S166512002013000100003\&lng=es\&nrm=iso>. ISSN 2594-0619

. 2008. "Paisaje: imagen, entorno, ensamble". Orbis Tertius 13 (14): 1-7. Disponible en: http://www.memoria.fahce.unlp.edu.ar/art_revistas/pr.3749/pr.3749.pdf

. 2000. Mapas de poder. Una arqueología literaria del espacio argentino. Rosario: Beatriz Viterbo Editora.

Bhabha, Homi. 2002. El lugar de la cultura. Buenos Aires: Manantial.

Calafell, Nuria. 2014. "Relato de un cuerpo en conflicto. XXY de Lucía Puenzo". Revista Letral 13: 53-62

Chefjec, Sergio. 2005. "La parte por el todo. Alegato oriental". En: El punto vacilante. Literatura, ideas y mundo privado. Buenos Aires: Norma. 35-42.

Kohan, Martín. 2002. "Partir sin partir del todo". Revista Todavía (En línea). Disponible en: http://www.revistatodavia.com.ar/todavia25/1.kohannota.html.

Fradinger, Moira. 2016. "Cuerpos anfibios: metamorfosis y anfientidad sexual en XXY (2007) de Lucía Puenzo”. Cuadernos de Literatura 20 (40): 369-393. https://doi. org/10.11144/Javeriana.cl20-40.came

cultura nacional al considerar la errancia, el exilio, el viaje y la extranjería como espacios y especialmente tiempos en los que el cuerpo es capaz de desactivar ciertos imperativos propios de la hegemonía sexual" (21). 
Guerrero, Javier. 2014. Tecnologías del cuerpo. Exhibicionismo y visualidad en América Latina. Madrid: Iberoamericana Vervuert.

Heffes, Gisela. 2013. Utopías urbanas: geopoliticas del deseo en América Latina. Madrid y Fráncfort del Meno: Iberoamericana/Vervuert.

Logie, Ilse. 2013. "Geografías ficcionales: El Uruguay de Copi”. Cuadernos LIRICO 8 [En línea]. Disponible en: http://lirico.revues.org/985.

Mairal, Pedro. 2016. La uruguaya. Buenos Aires: Planeta.

Pauls, Alan. 2006. La vida descalzo. Buenos Aires: Sudamericana.

Silvestri, Graciela. 2004. "Por qué los porteños soñamos con Montevideo". Revista Todavía 9 [En línea]. Disponible en: http://www.revistatodavia.com.ar/todavia09/notas/silvestri/txtsilvestri.html.

Tentoni, Valeria. 2016. "Parecidas pero diferentes". Eterna Cadencia. [En línea]. Disponible en: https://www.eternacadencia.com.ar/blog/contenidos-originales/entrevistas/ item/parecidas-pero-diferentes.html.

Waldegaray, Marta Inés. 2006. "El cruce al Uruguay: desplazamientos narrativos y espaciales en Los cautivos. El exilio de Echeverría, de Martín Kohan”. Confluencia. Revista Hispánica de Cultura y Literatura 22(1): 102-110. . 2013. “Travesías literarias entre dos orillas", Cuadernos LIRICO 8 [En línea]. Disponible en: http://journals.openedition.org/lirico/1033

Zizek, Slavoj. 2016. Problemas en el paraiso: del fin de la historia al fin del capitalismo. Barcelona: Anagrama 
